\title{
Hipnoterapia na Estética: Proposta de Estudos Para Aplicação da Hipnoterapia em Procedimentos Estéticos
}

\section{Alessandra Bertim Ramos*, Thaimara Cristina Guarnieri da Silva*, Ricardo Marques Kabzas, Sofia Poletti}

\section{Resumo}

A hipnoterapia se apresenta útil para sintomas de ansiedade, medo, analgesia, como anestésico em procedimentos odontológicos e em contextos cirúrgicos, sendo assim, uma proposta viável para amenizar os desconfortos nos procedimentos estéticos. O objetivo desta pesquisa é apresentar uma proposta de estudos para aplicação da hipnoterapia em procedimentos estéticos. A presente pesquisa está em desenvolvimento através de uma revisão literária, nas bases de dados Pubmed, SciELO e Google Acadêmico, com buscas de artigos científicos, dos últimos dez anos, nos idiomas Português e Inglês. Os estudos propostos, com a hipnoterapia como uma terapia complementar nos procedimentos estéticos, se justificam devido a alguns desses causarem desconforto como a dor. Portanto, espera-se com a presente pesquisa, propor estudos que venham evidenciar que a hipnoterapia possa contribuir para sessar ou amenizar os desconfortos provocados pelos procedimentos estéticos.

\section{Palavras-chave:}

Hipnose anestésica, Estética, Dor

\section{Introdução}

A hipnoterapia é reconhecida como uma terapia complementar pelo Conselho Federal de Medicina, reconhecida em diversas áreas tais como na Odontologia e procedimentos cirúrgicos. O objetivo da hipnoterapia é trabalhar no subconsciente da mente onde são armazenadas todas as experiências vividas e onde se encontra o nosso mecanismo de autoproteção e é neste ponto que a hipnose age (RIBEIRO, 2019). Alguns estudos mostram mudanças nas atividades de conectividade funcional do cérebro, diminuição da atividade no seu modo padrão e aumento da atividade do sistema pré-frontal após a indução hipnótica (HILTUNEN et al., 2019). Assim, o objetivo da presente pesquisa é apresentar uma proposta de estudos para aplicação da hipnoterapia em procedimentos estéticos.

\section{Resultados e Discussão}

Esta revisão de literatura foi aprovada pelo Comitê de Ética em Pesquisa da Fundação Hermínio Ometto - FHOl Uniararas, parecer 357/2019 e está em desenvolvimento. As bases de dados utilizadas: Publication Medical (Pubmed), Sciencie Eletronic Library On Line (SciELO) e Google Acadêmico, com artigos cientificos, dos últimos dez anos, nos idiomas Português e Inglês. Na literatura, até o momento, não foram encontrados estudos científicos com relatos da hipnoterapia em procedimentos estéticos. Porém, já é de conhecimento cientifico a eficácia da hipnoterapia em procedimentos odontológicos para analgesia (LUCAS, 2014; MONTENEGRO et al., 2017), como também para acesso venoso (HILTUNEN et al., 2019). Vários procedimentos estéticos causam desconforto como dor, ardência, edema, aumento de temperatura, os quais geram quadros de ansiedade (OGAWA, 2017). A dor é gerada por uma ação agressiva de forma térmica, mecânica ou química, que atingem receptores sensoriais mais profundos como vasos sanguíneos, músculos, vísceras, tecidos subcutâneos entre outros (CORADI, MENEGAZZI, VALDAMERI, 2010). A hipnose é definida por "um estado de consciência envolvendo atenção focada e consciência periférica reduzida (HILTUNEN et al., 2019).
A hipnoterapia é uma técnica de sedação não farmacológica que pode melhorar a experiência do paciente no controle da ansiedade, desconforto e dor, diferente de uma anestesia ou sedação famacológica, os quais podem levar a efeitos colaterais (LKINS et al., 2015). O estudo de Hiltunen et al. (2019), selecionou 148 pessoas que passaram por uma cirurgia de implantação por porta de acesso venoso, após 26 minutos de hipnose, concluiu que uma sessão de hipnose melhorou significativamente a satisfação dos mesmos. Montenegro et al. (2017) em um procedimento, induziu uma paciente a anestesia hipnótica durante um implante dentário, não fazendo o uso de anestesia farmacológica local. Logo após o procedimento e dentro de 24 horas não houve sangramento, edema, eritema e relato de dor, concluiu que a hipnoterapia fol eficaz em procedimentos cirúrgicos odontológicos na redução da ansiedade, sangramento e dor, minimizando o uso de anestésicos e efetuando o melhor resultado pósoperatório.

\section{Conclusões}

Espera-se com a presente pesquisa, propor estudos que venham evidenciar que a hipnoterapia possa contribuir para sessar ou amenizar os desconfortos provocados pelos procedimentos estéticos.

CORADI, M.; MENEGAZZI, P.D.; VALDAMERI, G.A. As sensações de dor nos procedimentos estéticos realizados pelos tecnólogos em cosmetologia e estética, Trabalho de Conclusão de Curso (Curso de Cosmetologia e Estética). 2010. 14f. Curso de Cosmetologia e Estética da Universidade do Vale do Itajaí - UNILAV, 2010.

HILTUNEN, S. et al. The effects of hypnosis and hypnotic Suggestions on the mismatch negativity in Highly hypnotizable subjects. International Journal of Clinical and Experimental Hypnosis, v. 67, n. 2, p.192-216, 2019.

LKINS,G.R. et al. Advancing Research and Practice: The Revised APA Division 30 Definition of Hypnosis. International Journal of Clinical and

Experimental Hypnosis, v. 63, n. 1, p. 1-9, 2015.

MONTENEGRO, G. et al. Hypnosis as a Valuable Tool for Surgical Procedures in the Oral and Maxillofacial Area. American Journal of Clinical Hypnosis, v. 59, n. 4, p. 414-421, 2017

OGAWA, A. Y.; BUCHI, A. T. Resultados de depilação a laser com a máquina Light Sheer. In: CONGRESSO NACIONAL DE INICIAÇÃO CIENTÍFICA n. 17, p. 1-7, 2017.

RIBEIRO, C. A Hipnoterapia como ferramenta de apoio para os tratamentos de doenças, OMNI Hypnosis Training Center 1. ed. atual. e rev. Mirandópolis, 2019 